Influence of soil qualities on intra- and interspecific competition dynamics of Larix kaempferi and L. olgensis

\title{
Guo, Qingxue
}

2017-03

Guo , Q, Zhang , Y , Wang , D , Zhang , Y , Korpelainen , H \& Li , C 2017 , ' Influence of soil qualities on intra- and interspecific competition dynamics of Larix kaempferi and L. olgensis ' , Environmental and Experimental Botany , vol. 135 , pp. 96-105 . https://doi.org/10.1016/j.envexpbot.2016.12.011

http://hdl.handle.net/10138/307845

https://doi.org/10.1016/j.envexpbot.2016.12.011

cc_by_nc_nd

acceptedVersion

Downloaded from Helda, University of Helsinki institutional repository.

This is an electronic reprint of the original article.

This reprint may differ from the original in pagination and typographic detail.

Please cite the original version. 
The revision for $\boldsymbol{E} E \boldsymbol{B}-\boldsymbol{D}-\mathbf{1 6 - 0 0 8 2 2}$

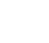

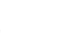

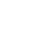

Influence of soil qualities on intra- and interspecific competition

dynamics of Larix kaempferi and L. olgensis

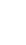

Qingxue Guo ${ }^{1,4}$, Yuanbin Zhang ${ }^{1}$, Danlin Wang ${ }^{1,4}$, Yunxiang Zhang 1, ,

Helena Korpelainen ${ }^{3}$ and Chunyang $\mathrm{Li}^{2, *}$

${ }^{1}$ Key Laboratory of Mountain Surface Processes and Ecological Regulation, Institute of Mountain Hazards and Environment, Chinese Academy of Sciences, Chengdu 610041, China

${ }^{2}$ College of Life and Environmental Sciences, Hangzhou Normal University, Hangzhou 310036, China

${ }^{3}$ Department of Agricultural Sciences, Viikki Plant Science Centre, P.O. Box 27, FI-00014 University of Helsinki, Finland

${ }^{4}$ University of Chinese Academy of Sciences, Beijing 100039, China

Correspondence: Chunyang Li, E-mail: licy@hznu.edu.cn

Running head: Effect of soil qualities on competition in Larix

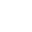

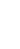


1 Abstract Forest management has potential to detrimentally impact long-term

2 plantation productivity. Establishment of mixed plantations and fertilization are two

3 important management approaches when trying to maintain soil qualities and

4 productivity. In this study, two types of experiments were conducted to investigate the

5 influence of soil qualities on intra- and interspecific competition dynamics in two

6 larch species. Experiment 1: We transplanted two deciduous larch species, Larix

$7 \quad$ kaempferi and L. olgensis, to study intra- and interspecific competition dynamics in

8 two different types of soil: one from a $c$. twenty years old L. kaempferi plantation

9 (named larch soil) and another from a secondary natural forest (named mixed-forest soil). Experiment 2: Effects of $\mathrm{N}$ fertilization on the competition dynamics of the two larch species were tested in the larch soil. In the experiment 1, we hypothesized that the growth of L. kaempferi in the larch soil under no fertilization is inhibited when competing with $L$. olgensis, and their competition relationships may be different in the mixed-forest soil. In both species, the starch and TNC (total non-structural carbohydrate) concentrations of roots and shoots were significantly higher in the mixed-forest soil when compared to the concentrations in the larch soil without $\mathrm{N}$ fertilization $(\mathrm{N}-)$. The relative competition intensity (RCI) was affected by the soil type. RCI of L. olgensis was higher than that of L. kaempferi in the larch soil Ncondition, and RCI of L. kaempferi was higher than that of L. olgensis in the mixed-forest soil in 2015. However, the RCI values did not show significant differences in 2014. In the experiment 2, L. kaempferi showed superior competitiveness in the larch soil N+ condition, with the highest RCI value in 2014, 
1 but the RCI value of L. kaempferi declined while the RCI value of L. olgensis

2 increased from 2014 to 2015 . Both experiments indicated that the benefiting species

3 had higher element (C, N and $\mathrm{P}$ ) and non-structural carbohydrate (starch and soluble

4 sugar) content accumulation ratios from 2014 to 2015. We found that competition

5 relationships changed between years and depending on conditions. We suggest that

6 mixed plantations and $\mathrm{N}$ fertilization together could effectively promote the

7 productivity of Larix.

8

9 Key-words: non-structural carbohydrate storage $\cdot$ environmental heterogeneity · temporal niche differentiation $\cdot$ forest management $\cdot$ forest plantation 
3 Although the total area of forests is declining globally, different types of forest 4 plantations are increasing. Forest plantations provide wood products to meet the social 5 and economic demands and help to restore degraded land (Paul et al., 2010; Gong et

\section{Introduction}

al., 2013). Yet, forest management has the potential to detrimentally impact long-term plantation productivity. The paper by Keeves (1966) drawed attention to potential productivity declines in successive rotations of Pinus radiata and, thereafter, many other studies have revealed similar results in different types of plantations around the world (reviewed by, e.g., Fox, 2000; O’Hehir and Nambiar, 2010). Several methods are available to solve such forest management problems. The establishment of mixed plantations and the use of fertilization are two important management approaches to maintain soil qualities and plantation productivity (Fox, 2000; O'Hehir and Nambiar, 2010; Richards et al., 2010).

The benefits of mixed-forest plantations are probably due to interactions between species or interactions with soils that are not present in monoculture plantations (Richards et al., 2010; Guo et al., 2016). Types of plant-plant competition (positive, negative or neutral) frequently shift or change in response to different environmental factors. As previously shown, spatial and temporal environmental heterogeneity can alter competitive relationships (Sthultz et al., 2007; Maestre et al., 2009; Soliveres et al., 2010; Liu et al., 2013; Biswas and Wagner, 2014). Species can distinguish 
conspecific and heterospecific individuals, and this may lead to substantial changes in interactions (Schmid and Kazda, 2002; Miller et al., 2007; Duan et al., 2014). Competitive responses are dynamic processes and they have been examined by many modelers (e.g., Damgaard et al., 2002; Crone, 2016). Several experiments have confirmed temporal changes in competition by measuring simultaneous changes in resource capture and biomass production (e.g. Trinder et al., 2012a, b). Typical one-time biomass measurements cannot provide unambiguous insights into the competition dynamics of plants.

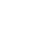

After several successive rotations, forest plantations typically show declined soil qualities, for example, lowered $\mathrm{N}$ availability to plants (Fox, 2000; O'Hehir and Nambiar, 2010). Thus, fertilization is an important way to ameliorate plantation soil qualities and promote productivity. Soil nutrient availability limits ecosystem productivity, either on their own or in combination with other mineral nutrients (Wassen et al., 2005). Plants have been shown to display different root distributions between conspecific and heterospecific species for resource capture (Schmid and Kazda, 2002). Many experiments have confirmed that plants' competitive interactions vary along with the availability and form of $\mathrm{N}$ or $\mathrm{P}$ (Maestre et al., 2005; Trinder et al., 2012b; Ahmad-Ramli et al., 2013; Wilberts et al., 2014), and negative competition reduces species richness (Hautier et al., 2009). Also, effects of forest plantations on soil microbial community structures could be an important reason that affects soil qualities and productivity. He et al. (2014) have shown that after the replacement of a 
natural broadleaf forest, bacteria with a close phylogenetic relationship to Pedobacter cryoconitis disappear, but those with a close phylogenetic relationship to Xanthomonas spp. and Rhodanobacter spp. begin to appear in the soil of a Cunninghamia lanceolata plantation.

(1)

The accumulation of $\mathrm{N}$ pools affects the performance and growth of plants (Jordan et al., 2012, 2014). Non-structural carbohydrates, the sum of soluble sugars and starch, play a key role in physiological processes, such as serving as signaling molecules, providing basic $\mathrm{C}$ energy to growth and respiration (Koch, 2004; Secchi and Zwieniecki, 2011) and maintaining cell turgor and osmoregulation (Muller et al., 2011). It has been shown that non-structural carbohydrate storage can enhance plants' ability to resist stress conditions (Myers and Kitajima, 2007; Wiley et al., 2013;

O'Brien et al., 2014). Non-structural carbon pools positively correlate with survival, especially when seedlings experience shade and defoliation (Myers and Kitajima, 2007). Species differ in the ways they produce, use, store and allocate non-structural carbohydrates, and this may determine their competitive ability. A few studies have found that intra- and interspecific competition modulates the concentration or accumulation of starch or soluble sugars (Liu et al., 2004; Duan et al., 2014; Guo et al., 2016). Differences in sizes of carbon pools are important functional traits that may reflect plants' competitive ability.

In this study, we conducted experiments to investigate intra- and interspecific 
competition dynamics in two deciduous tree species Larix kaempferi (Lamb.) Carr and L. olgensis A. Henry under two different soil types and under $\mathrm{N}$ fertilization. These two species are closely similar in life history traits and morphological traits, which make them difficult to be distinguished from each other, especially at the juvenile stage. However, they show differences in the growth rate, photosynthetic rate and N-use efficiency (Li et al., 2016). In the Experiment 1, we used one kind of soil from the L. kaempferi plantation and another type of soil from a natural secondary forest. We aimed to reveal the effects of the two soil types on competition dynamics. We hypothesized that the growth of L. kaempferi in the L. kaempferi soil under no fertilization is inhibited when competing with L. olgensis, and their competition relationships may be different in the soil sampled from the natural secondary forest. There is previous knowledge that a particular species may decline its growth in its own soil, while the growth of another species may not be negatively affected (Bever et al., 2012; Hendriks et al., 2015). In the Experiment 2, we studied the effects of $\mathrm{N}$ fertilization on the competition dynamics of the two larch species in the larch soil. Previously, Li et al. (2016) have shown that $\mathrm{N}$ fertilization promotes the growth of $L$. kaempferi in the L. kaempferi soil. We wanted to know, whether $\mathrm{N}$ fertilization would affect the competitive performance of the two larch species grown in the L. kaempferi soil. Finally, we wanted to know how the plants' nutrition and non-structural carbohydrate accumulation are affected by competition. 


\section{Methods and materials}

\subsection{Study site and experimental design} Institute of Applied Ecology, Chinese Academy of Sciences, located in a mountainous region in the eastern Liaoning Province, Northeast China ( $\left.41^{\circ} 51^{\prime} \mathrm{N}, 124^{\circ} 54^{\prime} \mathrm{E}\right)$. Larch forests are the dominant forest plantation type through northeastern Asia to central Siberia (Liang et al., 2004). The studied species, L. kaempferi and L. olgensis, are the major plantation tree species in cold and medium temperate zones of China. Two different soil types were used and they originated from a $c$. twenty years old planted forest community of L. kaempferi and from a natural secondary forest community. Quercus mongolica and Juglans mandshurica are the dominant tree species in the natural secondary forest. Hereafter, we call the two types of soil larch soil and mixed-forest soil, respectively. The sampled soil was homogenized before planting. The two types of soil were different in their physical and chemical properties. The former type of soil ( $\mathrm{pH} 5.65, \mathrm{C} 18.61 \mathrm{~g} \mathrm{~kg}^{-1}, \mathrm{~N} 1.82 \mathrm{~g} \mathrm{~kg}^{-1}, \mathrm{P} 4.38 \mathrm{~g} \mathrm{~kg}^{-1}$ ) is light brown and the percentage of gravel $(>2 \mathrm{~mm})$ averages $7.28 \%$, while the latter type of

22 soil ( $\mathrm{pH} 6.24, \mathrm{C} 42.78 \mathrm{~g} \mathrm{~kg}^{-1}, \mathrm{~N} 3.89 \mathrm{~g} \mathrm{~kg}^{-1}, \mathrm{P} 6.01 \mathrm{~g} \mathrm{~kg}^{-1}$ ) is dark and the percentage 
of gravel averages $21.37 \%$.

\subsection{Experiment 1: two soil types}

The intra- and interspecific competition treatments were designed as follows: monoculture plantations reflecting intraspecific, competition L. kaempferi + L. kaempferi and L. olgensis + L. olgensis; mixed cultures representing interspecific competition, L. kaempferi + L. olgensis. This experiment aimed to reveal the soil effect on the competition dynamics of the two species. Three competition treatments and two soil types (larch and mixed-forest soil) were set up.

\subsection{Experiment 2: N supplied to the larch soil}

Effects of $\mathrm{N}$ fertilization were tested only in the larch soil. Urea $(46.3 \% \mathrm{~N})$ was used for $\mathrm{N}$ fertilization (as in Zhu et al. 2011) in the monocultures and mixed plantations of both species using larch soil. We added urea twice a year, in May and June (5.1 g each time) during years 2014 and 2015. The urea was homogeneously applied to each pot, which were immediately watered. Three competition treatments and two $\mathrm{N}$ conditions (with and without $\mathrm{N}$ fertilization) were set up. Thus, in the larch soil, there were three treatments without $\mathrm{N}$ fertilization: two monoculture plantations (Mo), one for each species, and one mixed culture (M), and three additional treatments with $\mathrm{N}$ fertilization: two monoculture plantations, one for each species (PN) and one mixed 
1 plantation $(\mathrm{MN})$. Competition treatments were the same as in experiment 1 . The three

5 One-year old seedlings with approximately the same crown size and height (no treatments without $\mathrm{N}$ fertilization in experiment 2 were the same as the three treatments in the larch soil in experiment 1. significant statistical differences) were selected from a local nursery garden. In late October, 2013, two seedlings were planted in each plastic pot (external diameter and height $56 \mathrm{~cm}$ and $33 \mathrm{~cm}$, respectively) to set up intra- and interspecific competition treatments for both species using two different types of soil (c. $70 \mathrm{~kg}$ soil per pot). Sixteen replicates per treatment were included in the study. Additionally, three individuals of each species were grown singly $(\mathrm{S})$ in each type of soils and in the $\mathrm{N}$ fertilized larch soil (SN).

\subsection{Harvesting and measurements}

We harvested plants twice, on the $29^{\text {th }}$ of August, 2014 and $4^{\text {th }}$ of September, 2015. In 2014, four pots from each treatment were randomly harvested and all individuals were divided into leaves, shoots and roots. In 2015, four or five pots from each treatment were selected and the harvested individuals were divided into leaves, branches, stems, coarse roots (diameter $>2 \mathrm{~mm}$ ) and fine roots (diameter $<2 \mathrm{~mm}$ ). All harvested plants were dried at $70{ }^{\circ} \mathrm{C}$ for $72 \mathrm{~h}$. Three replicates from single plantation patterns ( $\mathrm{S}$ and SN) were harvested only in 2015. All dried materials were ground into a power for 
3 We measured the concentrations of C, N, P, starch and soluble sugars in each part of

4 the harvested materials. The $\mathrm{C}, \mathrm{N}$ and $\mathrm{P}$ concentrations were determined by the rapid 5 dichromate oxidation technique (Nelson and Sommers, 1982), the semi-micro

6 Kjeldahl method (Mitchell, 1998) and the vanadate-molybdate yellow colorimetric

further measurements.

method (Yang et al., 2011) after minor modifications. Methodological details of the measurements of starch and soluble sugars were described by Guo et al. (2016).

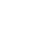

\subsection{Data analysis}

Firstly, we calculated the relative competitive intensity (RCI) of both species when exposed to different competition treatments, $\mathrm{N}$ fertilization or soil types in 2014 and 2015, according to the formula described by Grace (1995) as follows:

$\mathrm{RCI}=\mathrm{Bc}-\mathrm{Bs} / \mathrm{Bs}$

Where $\mathrm{Bc}$ represents the total biomass of an individual from interspecific competition and Bs represents the average total biomass of corresponding plants from intraspecific competition. Positive RCI value stands for a better growth with a heterospecific species than with a conspecific one.

Secondly, we calculated the concentration dynamics of C, N, P and non-structural carbohydrates (starch, soluble sugars and total non-structural carbohydrates TNC) of 
1 each plant organ during both years. TNC of each organ was the sum of its starch and

2 soluble sugars. The formula was as follows:

3 Concentration variation $=\left[\right.$ Concentration $_{2015}-$ Concentration $\left._{2014}\right] /$ Concentration $_{2014}$,

4 where Concentration 2015 and Concentration 2014 represented the concentrations of C, N,

$5 \quad \mathrm{P}$ and non-structural carbohydrates in 2015 and 2014, respectively. In 2015, we

6 defined the shoot as the sum of branches and stems. Concentrations of shoots were

7 calculated as follows:

8 Concentration $=\left[\right.$ BioBranch $\times$ Concentration $_{\text {Branch }}+$ BioStem $\times$ Concentration $\left._{\text {Stem }}\right] /$

$9\left[\mathrm{Bio}_{\mathrm{Branch}}+\mathrm{Bio}_{\mathrm{Stem}}\right]$, where Bio Branch and Biostem represent branch and stem biomasses, 10 respectively.

11 Similarly, concentrations of roots were computed as follows:

12 Concentration $=\left[\right.$ Bio $_{\text {Coarse }} \times$ Concentration $_{\text {Coarse }}+$ Bio Fine $\times$ Concentration $\left._{\text {Fine }}\right] /$ 13 [Biocoarse + Biofine], where Biocoarse and Biofine represent biomasses of coarse and fine 14 roots, respectively.

Changes in the contents of C, N, P and non-structural carbohydrates (starch, soluble sugars and TNC) were calculated as follows: Content accumulation $=\left[\right.$ Content $_{2015}-$ Content 2014] / Content 2014, where Content 2015 and Content 2014 represent the contents 19 of C, N, P and non-structural carbohydrates in 2015 and 2014, respectively. The content of each plant part, for instance, the leaf $\mathrm{N}$ content of an individual was

21 obtained by multiplying the leaf $\mathrm{N}$ concentration by leaf biomass. In 2015 , the contents of shoots were the sum of branch and stem contents. 
2 Data were checked for normality and the homogeneity of variances. Parameters were

3 log-transformed when needed. Tukey's $b$ tests were carried out for each species to

4 detect their RCI differences among treatments. Three-way analyses of variance

5 (ANOVA) were performed for individuals grown in the larch soil to detect the effects

6 of species, competition treatment and $\mathrm{N}$ fertilization. When significant interactions

7 were observed, Tukey's $b$ tests were conducted as post hoc tests to discover

8 significant differences among treatments. Similarly, two-way analyses of variance

9 were performed for individuals grown in the mixed-forest soil to discover the effects

10 of species and competition patterns. If a significant factor interaction between species

11 and competition was found, Tukey's $b$ tests were conducted as well. In order to

12 discover the effects of soil type, an Independent-Samples T test was conducted for the

13 same species in the same competition treatment but grown in two types of soil. All

14 data were analyzed with the software Statistical Package for the Social Science (SPSS)

15 version 20.0 . 


\section{Results}

\subsection{Relative competitive intensity}

The results showed that the relative competitive intensity (RCI) of the two species was influenced by the competition treatment, $\mathrm{N}$ fertilization or soil type. More importantly, RCI showed considerable temporal changes from 2014 to 2015 (Fig. 1). In 2014, the RCI value of L. kaempferi was significantly higher when grown with $L$. olgensis in the $\mathrm{N}$-fertilized larch soil than in other treatments, while no other treatment differences were detected. Thus, the growth of L. kaempferi was facilitated by L. olgensis under $\mathrm{N}$ fertilization (Fig. 1a). In 2015, the RCI value of L. olgensis was higher than that of L. kaempferi in the larch soil N-, whereas the RCI of $L$. kaempferi was higher than that of L. olgensis in the mixed-forest soil (Fig. 1b). During the second year, after $\mathrm{N}$ fertilization in the larch soil, the RCI of L. kaempferi was still higher compared to that of L. kaempferi in the larch soil N-. However, the RCI of L. olgensis was higher compared to that of L. olgensis in the mixed-forest soil (Fig. 1b).

22 When compared with individuals grown alone without any competition, intra- and 
1 interspecific competition declined the biomass of both studied species (Table 1). In

2 the larch soil $\mathrm{N}+$ condition, the growth of L. kaempferi was much greater under $\mathrm{MN}$

3 (mixed culture with $\mathrm{N}$ fertilization) and it exhibited significantly higher biomasses of

4 coarse roots, fine roots, total roots and whole individuals when compared with PN

5 (monoculture with $\mathrm{N}$ fertilization). A positive growth response was found also in the

6 mixed culture (M) in L. olgensis, whose biomasses (e.g. branches and leaves) were

7 significantly higher than those of plants grown in the monoculture (Mo) in the larch

8 soil $\mathrm{N}$ - condition. However, the relationship shifted between the two species in the

9 mixed-forest soil. Specifically, the growth of L. kaempferi greatly benefited from the

10 presence of L. olgensis, as a greater total biomass difference between $\mathrm{M}$ and Mo was

11 detected (Table 1).

\subsection{Concentration variation}

Single factors (competition, species or $\mathrm{N}$ fertilization) or their interactions caused temporal variation in $\mathrm{C}, \mathrm{N}$ and $\mathrm{P}$ concentrations, except for the concentration of leaf $\mathrm{C}$ and shoot $\mathrm{C}$ in different soil types (see Table S1 in Supplementary materials). In the larch soil $\mathrm{N}$ - condition, the root $\mathrm{C}$ concentration of both species was significantly greater in mixed cultures (M) compared to monocultures (Mo), and this difference disappeared in the larch soil $\mathrm{N}+$ condition (Fig. 2a). The leaf $\mathrm{N}$ concentration of $L$. kaempferi from the monoculture (Mo) was significantly higher than that of individuals grown under interspecific competition (M) in the larch N- soil (Fig. 2b). 
1 In the mixed-forest soil, both leaf and shoot $\mathrm{N}$ concentrations of $L$. olgensis from

2 mixed culture (M) were significantly lower compared with L. olgensis grown in 3 monocultures (Mo) (Fig. 2b). The shoot $\mathrm{P}$ concentration of L. kaempferi from $\mathrm{MN}$

4 was significantly lower compared with the same species from $\mathrm{PN}$ in the larch soil $\mathrm{N}+$

5 condition (Fig. 2c). N and P concentration variation between the two soil types were

6 also observed, for example, leaf $\mathrm{N}$ and leaf $\mathrm{P}$ concentrations of L. kaempferi from the

7 mixed culture (M) in the mixed-forest soil were significantly higher than those of $L$.

8 kaempferi from the mixed culture (M) in the larch soil N- condition (Fig. 2b, c).

10 In larch soil N- condition, concentrations of shoot starch, soluble sugars and TNC as 11 well as of leaf starch and TNC of L. kaempferi from mixed culture (M) increased 12 more than those of individuals from L. kaempferi monoculture (Mo); by contrast, 13 concentrations of root soluble sugars and root TNC of L. kaempferi were significantly 14 higher in Mo (Fig. 2d, e, f). In L. olgensis, a significant concentration change was 15 found only in root starch, which was higher in M than in Mo in the larch soil N16 condition (Fig. 2d). In the mixed-forest soil, significant interactions of competition 17 and species concerning the starch concentration of shoots and roots were observed 18 (Table S1). Concentrations of root starch, root soluble sugar and root TNC of $L$. 19 kaempfer from the mixed culture were significantly higher in the mixed-forest soil 20 compared with those of L. kaempfer in the larch soil N- condition (Fig. 2d, e, f). 
2 Different factors (competition, $\mathrm{N}$ fertilization and species) alone or their interactive

3 effects influenced $\mathrm{C}, \mathrm{N}$ and $\mathrm{P}$ contents of plant organs, as well as those of whole

4 plants in different soils (Tables S2, S3 and S4 in Supplementary materials). We

5 discovered that the growth of L. kaempferi greatly benefited from the presence of $L$.

6 olgensis in the mixed-forest soil and it tended to have a significantly higher $\mathrm{C}$

7 accumulation or $\mathrm{N}$ pool size in leaves and shoots and in the whole individual (Tables

$8 \quad \mathrm{~S} 2$ and S3).

In the larch soil $\mathrm{N}$ - condition, $\mathrm{C}, \mathrm{N}$ and $\mathrm{P}$ content accumulation ratios of roots and

11 shoots of L. olgensis were significantly higher in the mixed culture (M) when compared with monoculture (Mo), while L. kaempferi in the mixed-forest soil exhibited similar values in the mixed culture and monoculture (Fig. 3a, c, e). Corresponding results were observed at the whole plant level (Fig. 3b, d, f). In the larch soil $\mathrm{N}+$ condition, the accumulation ratios of root $\mathrm{C}$, shoot $\mathrm{C}$, leaf $\mathrm{N}$, shoot $\mathrm{P}$ and root $\mathrm{P}$ as well as the accumulation ratios of $\mathrm{C}, \mathrm{N}$ and $\mathrm{P}$ of whole individuals of $L$. olgensis were significantly higher in the mixed culture (MN) compared with the monoculture (PN), while the whole plant $\mathrm{P}$ accumulation ratio of L. kaempferi tended to decrease more in the mixed culture $(\mathrm{MN})$ (Fig. 3). There were tendencies that $\mathrm{C}, \mathrm{N}$ and $\mathrm{P}$ accumulation ratios were higher in the mixed-forest soil (Fig. 3). 
2 Different factors (competition, $\mathrm{N}$ fertilization and species) alone as well as their

3 interactive effects influenced starch, soluble sugar and TNC contents of plant organs

4 as well as those of whole plants (Tables S3, S5 and S6 in Appendix). The species

5 benefiting from the presence of another species when growing in different types of

6 soil tended to have higher non-structural carbohydrate contents (Tables S3 and S5).

8 In the larch soil N- condition, the contents of starch (roots and shoots), root soluble 9 sugars and TNC (roots and shoots), as well as those of whole plants of L. olgensis became significantly higher in the mixed culture (M) compared with the monoculture (Mo) (Fig. 4). Under $\mathrm{N}$ fertilization in the larch soil, contents of starch (roots, shoots and whole plant), soluble sugars (leaves and whole plant) and TNC (shoots, leaves and whole plant) of L. kaempferi were negatively affected by the presence of $L$. olgensis (Fig. 4). In the mixed-forest soil, starch (shoots, whole plant) and both soluble sugars and TNC (roots, shoots, leaves and whole plant) of L. kaempferi increased under the presence of L. olgensis, while the contents of root soluble sugars in L. olgensi decreased under the presence of L. kaempferi (Fig. 4). There were also tendencies that the starch, soluble sugars and TNC accumulation ratios were higher in the mixed-forest soil (Fig. 4). 
3 Ecologists have suggested that both negative and positive competition play important

4 roles in the structuring of populations and communities in the nature (Bertness and

5 Callaway, 1994; Trinder et al., 2013; Biswas and Wagner, 2014). Through different

\section{Discussion}

experiments in diverse environments, researchers try to find explanations for how and to what extent neighboring organisms influence competition dynamics. In our study, we discovered that the soil type has an important role in determining competition relationships.

\subsection{Competition dynamics responding to $N$ fertilization}

Tilman's theory (1987) suggests that competition for soil nutrients is stronger at low nutrient levels compared with high nutrient levels, while the stress gradient hypothesis (Bertness and Callaway, 1994) proposes that individuals of different species may negatively compete for resources or space in a productive environment but they may positively compete (facilitate) in a severe environment, and there is a possibility for intraspecific competition for the same resources or space (Miller, 1996; Goldenheim et al., 2008; Maestre et al., 2009; Fajardo and McIntire, 2011; Liu et al., 2013). In the productive soil (larch soil $\mathrm{N}+$ ), L. kaempferi showed strong positive inter-specific competition and some negative effects on the growth of L. olgensis in 2014 (Fig. 1a), which partly supported the stress gradient hypothesis. Also previously, L. kaempferi 
1 has been shown to exhibit early superiority that is greatly facilitated by the presence

2 of L. olgensis in the larch soil $\mathrm{N}+$ (total biomasses: L. kaempferi $74.80 \mathrm{~g}$ vs. L.

3 olgensis $29.22 \mathrm{~g}, P<0.05$; Guo et al., 2016). In 2015, RCI of L. olgensis greatly

$4 \quad$ increased and RCI of L. kaempferi was still higher, although slightly lower compared

5 to the value in 2014 in the larch soil N+ (Fig. 1b). The growth of L. olgensis was no

6 longer inhibited by the presence L. kaempferi and its biomass was significantly higher

7 than that in monoculture in the larch soil $\mathrm{N}+$ condition (Table 1), which then partly

8 supported the Tilman's theory (1987). Therefore, our results did not fully support

9 either of the two contrasting competition theories.

\subsection{Competition dynamics responding to soil type}

Our results provided evidence that the competitive performance of the two Larix species was different in the larch soil N- condition and in the mixed-forest soil. Many studies have proposed that the effects of the plant-soil feedback are plant species-specific and negative (Kulmatiski et al., 2008; van der Putten et al., 2013; Hendriks et al., 2015). Successive plantation cycles reduce productivity due to negative effects on soil qualities (Fox, 2000; O’Hehir and Nambiar, 2010). Starch and TNC concentrations of shoots and roots in L. kaempferi from monoculture in larch soil $\mathrm{N}$ - condition were significantly lower than those in L. kaempferi from monoculture in mixed-forest soil (Fig. 2d, f). Furthermore, the starch and TNC contents and accumulation ratios also showed similar patterns (Table S5; Fig. 4). 
1 Therefore, the negative effects of larch soil on L. kaempferi were probably the reason

2 that determined its negative performance in interspecific competition with $L$. olgensis

3 in the larch soil N- condition at 2015 (Fig. 1b).

4

5 When a plant is confronted with foreign soil, root growth may be accelerated

6 (Hendriks et al., 2015). Resource exploration has long been considered as a major

7 mechanism determining the success of several invasive species (Levine et al., 2003).

8 The root (including fine and coarse root) growth of L. olgensis was markedly

$9 \quad$ inhibited by L. kaempferi when compared with L. olgensis monoculture grown in the

10 mixed-forest soil in 2015 (Table 1). This indicated that L. kaempferi was a strong

11 competitor to capture and store nutrition relative to L. olgensis, when they interacted

12 in foreign soil (Fig. 2, 3), which probably increased its C fixation and simultaneously

13 accelerated both growth and carbon storage (Fig. 4).

\subsection{Temporal changes in competition}

Crone (2016) stated that the effects of among-site variation and among-year variation (environmental stochasticity) are important for the population dynamics of Pulsatilla patens, as revealed by a 10-year demographic monitoring study. Intraspecific competition of Alliaria petiolata was found to show seasonal variation in both experimental and field conditions; specifically, statistically significant negative density-dependent survival during the productive summer period and positive 
1 density-dependent survival over the severe winter period were observed (Biswas and

2 Wagner, 2014). The temporal determinants of responses of forest tree species to

3 climatic changes are important for forest dynamics. For example, Linares et al. (2010)

4 suggested that the growth decline and death of Abies pinsapo occurred as a result of

5 interacting effects of both competition and climate stressors acting at long- and

6 short-term time scales. In our study, although we regularly watered the plants to meet

7 their specific water demand, variation in climate conditions, such as the amount of

8 rainfall, was not measured during the experiments. However, we did find temporal

9 changes, as there were interacting effects of competition and soil qualities. Temporal

10 variation in the competition dynamics was also detected between the larch soil $\mathrm{N}$ -

11 condition and the mixed-forest soil from 2014 to 2015. Total biomasses of the two

12 species grown together were not significantly different in 2014 (L. kaempferi 31.09 vs

13 L. olgensis 21.00, $P>0.05$, larch soil, Guo et al. 2016; L. kaempferi 21.17 vs $L$.

14 olgensis $29.64, P>0.05$, mixed-forest soil, data unpublished) and their RCIs showed

15 no differences (Fig. 1a). However, L. olgensis benefited from the presence of $L$.

16 kaempferi in the larch soil $\mathrm{N}$ - condition, while L. kaempferi benefited from the

17 presence of L. olgensis in the mixed-forest soil in 2015 (Figs. 1b and 5; Table 1). We

18 concluded that soil type effects on competition show temporal variation and species

19 may need a relatively long time to provide proof of their competitive ability.

21 Through our experiments, we revealed that the resource accumulation dynamics is tightly coupled with the temporal dynamics of species competition. As shown 
1 previously, $\mathrm{N}$ accumulation by Plantago lanceolata exceeded that of Dactylis

2 glomerata during the first 62 days, but, thereafter, D. glomerata accumulated more N,

3 which indicated temporal variation in competitive interactions (Trinder et al., 2012a).

4 Neighbors may affect non-structural carbohydrate concentrations, which then

5 influence competition performance under different environmental conditions

6 (Anderson et al., 2001; Liu et al., 2004; Duan et al., 2014). Apparently, in our study,

7 there was temporal variation in the concentration dynamics of non-structural

8 carbohydrates (Fig. 2). Resource (N and P) resorption making plants less dependent

9 on the availability of nutrients is a critical strategy in nutrient conservation, especially

10 in deciduous species. Resource resorption is affected by nutrient addition (Lü et al.,

11 2013; Mayor et al., 2014), and nutrient residence times or resorption efficiency are

12 different in interspecific and intraspecific competition (reviewed by Richards et al.,

13 2010). Non-structural carbohydrates can be reallocated from foliar to other plant parts.

14 The process of resorption may also show temporal variation and may affect

15 competition dynamics, although we did not explored it in this study.

\subsection{Storage and competition}

Plants can potentially buffer environmental changes or stochasticity by using stored resources. Many reports have depicted the role of non-structural carbohydrates in determining tolerance to severe stress, like shade and drought (Myers and Kitajima, 2007; Adams et al., 2013; O'Brien et al., 2014). Stored nutrients affect plant growth 
1 and performance (Pellicer et al., 2000; Uhde-Stone et al., 2003; Jordan et al., 2012, 2 2014). Pellicer et al. (2000) suggested that the rooting of leafy cuttings of Larix $\times$

3 eurolepis was limited by the initial amount of $\mathrm{N}$ reserves. In our study, the benefiting

4 species possessed a higher amount of nutrients and non-structural carbohydrates, as

5 well as a stronger $\mathrm{C}$ accumulation compared to its neighbors. Probably our results

6 partly answered, why some mixed cultures were more resistant to disturbances than

7 monocultures.

9 Plant species are thought to have a high year-round content of non-structural carbohydrates regardless of seasonal fluctuations, habitat and climate (Hoch et al., 11 2003; Körner, 2003; Würth et al., 2005). Carbohydrate pools stored in aboveground parts of mature deciduous trees are estimated to be sufficient to replace the entire leaf canopy four times in the absence of photosynthesis (Hoch et al., 2003). However, a considerable fraction of the starch pool stored in the xylem becomes sequestered (Millard et al., 2007) and fails to be used (Sala et al., 2010). Although L. kaempferi exhibited the highest contents of starch and soluble sugar when planted with $L$. olgensis in the larch soil $\mathrm{N}+$ condition in 2014, we observed that the RCI of $L$. kaempferi declined along with the increasing RCI of L. olgensis in 2015 when growing in the larch soil $\mathrm{N}+$ condition (Fig. 1b). Consequently, the element (C, N and P) and non-structural carbohydrate accumulation ratios of L. kaempferi were significantly influenced by competition with L. olgensis in the larch soil $\mathrm{N}+$ condition

22 (Figs. 3 and 4). 
4 Competition interactions are always regulated by resource partitioning, such as

5 preferences for different nutrient forms in soil (McKane et al., 2002; Turner, 2008;

6 Ahmad-Ramli et al., 2013). The preference for $\mathrm{P}$ forms regulates the competitive

7 outcomes between Vaccinium vitis-idaea and Deschampsia cespitosa (Ahmad-Ramli

8 et al., 2013). As shown previously, the two studied Larix species have different

9 growth traits; for example, the net photosynthesis rate and content of non-structural carbohydrates of L. kaempferi are significantly higher than those of L. olgensis in normal conditions ( $\mathrm{Li}$ et al., 2016). Differences in carbohydrate storage can explain species coexistence (Myers and Kitajima, 2007). Temporal changes in plant traits, such as root biomass and starch content of L. olgensis from 2014 to 2015 in two types of soil led to changes in resource competition. Resource competition is dependent on the spatial and temporal distribution of resources between species (Alpert et al., 2000). Soil reduces establishment and growth for some species, while other plant species are less harmed. Species are probably different in their demands, and there may be temporal niche differentiation. In Larix, competition dynamics is evidently regulated by the combined effects of species, soil type and temporal variation, which contribute to the coexistence of species and to the dynamics of their communities.

\section{Conclusions}


2 Our study revealed the effects of soil type on the competition dynamics of the two

3 Larix species. $\mathrm{N}$ fertilization was found to be an effective method for promoting the

4 productivity of Larix plantations. The results indicated that $\mathrm{N}$ fertilization alleviated

5 the negative effects of L. kaempferi soil on the growth of L. kaempferi and promoted

6 the growth of both species when they were grown in a mixed culture.

7

8

Author Contribution Statement Qingxue Guo had the main responsibility for data collection, analysis and writing, Yuanbin Zhang had a significant contribution to data collection and analysis, Danlin Wang and Yunxiang Zhang had significant contributions to data collection and experimental arrangements, Helena Korpelainen had a significant contribution to the interpretation of data and manuscript preparation, and Chunyang $\mathrm{Li}$ (the corresponding author) had the overall responsibility for experimental design and project management.

Acknowledgements This work was supported by the Talent Program of Hangzhou Normal University (2016QDL020). We are very grateful to the Qingyuan Experimental Station, Institute of Applied Ecology, Chinese Academy of Sciences for providing experimental sites and support. 
2 Adams, H.D., Germino, M.J., Breshears, D.D., Barron-Gafford, G.A., Guardiola-Claramonte, M., Zou, C.B., Huxman, T.E., 2013. Nonstructural leaf carbohydrate dynamics of Pinus edulis during drought-induced tree mortality reveal role for carbon metabolism in mortality mechanism. New Phytologist $197,1142-1151$.

Ahmad-Ramli, M.F., Cornulier, T., Johnson, D., 2013. Partitioning of soil phosphorus regulates competition between Vaccinium vitis-idaea and Deschampsia cespitosa. Ecology and Evolution 3, 4243-4252.

Alpert, P., Bone, E., Holzapfel, C., 2000. Invasiveness, invasibility and the role of environmental stress in the spread of non-native plants. Perspectives in Plant Ecology, Evolution and Systematics 3, 52-66.

Anderson, C.P., Hogsett, W.E., Plocher, M., Rodecap, K., Lee, E.H., 2001. Blue wild-rye grass competition increases the effect of ozone on ponderosa pine seedlings. Tree Physiology 21, 319-327.

Bertness, M.D., Callaway, R., 1994. Positive interactions in communities. Trends in Ecology \& Evolution 9, 191-193.

Bever, J.D., Platt, T.G., Morton, E.R., 2012. Microbial population and community dynamics on plant roots and their feedbacks on plant communities. Annual Review of Microbiology 66, 265-283.

Biswas, S.R., Wagner, H.H., 2014. A temporal dimension to the stress gradient hypothesis for intraspecific interactions. Oikos 123, 1323-1330. 
1 Crone, E.E., 2016. Contrasting effects of spatial heterogeneity and environmental stochasticity on population dynamics of a perennial wildflower. Journal of Ecology 104, 281-291.

Damgaard, C., Weiner, J., Nagashima, H., 2002. Modelling individual growth and competition in plant populations: growth curves of Chenopodium album at two densities. Journal of Ecology 90, 666-671.

Duan, B.L., Dong, T.F., Zhang, X.L., Zhang, Y.B., Chen, J., 2014. Ecophysiological responses of two dominant subalpine tree species Betula albo-sinensis and Abies faxoniana to intra- and interspecific competition under elevated temperature. Forest Ecology and Management 323, 20-27.

Fajardo, A., McIntire, E.J.B., 2011. Under strong niche overlap conspecifics do not compete but help each other to survive: facilitation at the intraspecific level. Journal of Ecology 99, 642-650.

Fox, T.R., 2000. Sustained productivity in intensively managed forest plantations. Forest Ecology and Management 138, 187-202.

Goldenheim, W.M., Irving, A.D., Bertness, M.D., 2008. Switching from negative to positive density-dependence among populations of a cobble beach plant. Oecologia 158, 473-483.

Grace, J.B., 1995. On the measurement of plant competition intensity. Ecology 76, 305-308.

Guo, Q.X., Li, J.Y., Zhang, Y.X., Zhang, J.X., Lu ,D.L., Korpelainen, H., Li, C.Y., 2016. Species-specific competition and $\mathrm{N}$ fertilization regulate non-structural 
carbohydrate contents in two Larix species. Forest Ecology and Management $364,60-69$.

Hautier, Y., Niklaus, P.A., Hector, A., 2009. Competition for light causes plant biodiversity loss after eutrophication. Science 324, 636-638.

He, Y.H., Zhou, G.Y., Wang, S.J., Li, H. 2014. Fungal diversity in Cunninghamia lanceolata plantation soil. Acta Ecologica Sinica, 34, 2725-2736.

Hendriks, M., Ravenek, J.M., Smit-Tiekstra, A.E., van der Paauw, J.W., de Caluwe, H., van der Putten, W.H., de Kroon, H., Mommer, L., 2015. Spatial heterogeneity of plant-soil feedback affects root interactions and interspecific competition. New Phytologist 207, 830-840.

Hoch, G., Körner, C., 2003. The carbon charging of pines at the climatic treeline: a global comparison. Oecologia 135, 10-21.

Jordan, M-O., Vercambre, G., Gomez, L., Pagès, L., 2014. The early spring N uptake of young peach trees (Prunus persica) is affected by past and current fertilizations and levels of C and N stores. Tree Physiology 34, 61-72.

Jordan, M-O., Wendler, R., Millard, P., 2012. Autumnal N storage determines the spring growth, $\mathrm{N}$ uptake and $\mathrm{N}$ internal cycling of young peach trees. Trees 26, 393-404.

Keeves, A., 1966. Some evidence of loss of productivity with successive rotations of Pinus radiata in the south-east of South Australia. Australian Forestry 30, $51-63$.

Körner, C., 2003. Carbon limitation in trees. Journal of Ecology 91, 4-17. 
1 Koch, K., 2004. Sucrose metabolism: regulatory mechanisms and pivotal roles in sugar sensing and plant development. Current Opinion in Plant Biology 7, $235-246$.

Kulmatiski, A., Beard, K.H., Stevens, J.R., Cobbold, S.M., 2008. Plant-soil feedbacks: a meta-analytical review. Ecology Letters 11, 980-992.

Liang, N., Nakadai, T., Hirano, T., Qu, L., Koike, T., Fujinuma, Y., Inoue, G., 2004. In situ comparison of four approaches to estimating soil $\mathrm{CO}_{2}$ efflux in a northern larch (Larix kaempferi Sarg.) forest. Agricultural and Forest Meteorology 123, 97-117.

Lü, X.T., Reed, S., Yu, Q., He, N.P., Wang, Z.W., Han, X.G., 2013. Convergent responses of nitrogen and phosphorus resorption to nitrogen inputs in a semiarid grassland. Global Change Biology 19, 2775-2784.

Levine, J.M., Vila, M., D'Antonio, CM., Dukes, J.S., Grigulis, K., Lavorel, S., 2003. Mechanisms underlying the impacts of exotic plant invasions. Proceedings of the Royal Socity of London B-Biolgical Sciences 270, 775-781.

Li, J.Y., Guo, Q.X., Zhang, J.X., Korpelainen, H., Li, C.Y., 2016. Effects of nitrogen and phosphorus supply on growth and physiological traits of two Larix species. Environmental and Experimental Botany 130, 206-215.

Linares, J.C., Camarero, J.J., Carreira, J.A., 2010. Competition modulates the adaptation capacity of forests to climatic stress: insights from recent growth decline and death in relict stands of the Mediterranean fir Abies pinsapo. Journal of Ecology 98, 592-603. 
1 Liu, N., Ren, H., Yuan, S.F., Guo, Q.F., Yang, L., 2013. Testing the stress-gradient hypothesis during the restoration of tropical degraded land using the shrub Rhodomyrtus tomentosa as a nurse plant. Restoration Ecology 21, 578-584.

Liu, X., Kozovits, A.R., Grams, T.E.E., Blaschke, H., Rennenberg, H., Matyssek, R., 2004. Competition modifies effects of enhanced ozone/carbon dioxide concentrations on carbohydrate and biomass accumulation in juvenile Norway spruce and European beech. Tree Physiology 24, 1045-1055.

Maestre, F.T., Bradford, M.A., Reynolds, J.F., 2005. Soil nutrient heterogeneity interacts with elevated $\mathrm{CO}_{2}$ and nutrient availability to determine species and assemblage responses in a model grassland community. New Phytologist 168, 637-650.

Maestre, F.T., Callaway, R.M., Valladares, F., Lortie, C.J., 2009. Refining the stress-gradient hypothesis for competition and facilitation in plant communities. Journal of Ecology 97, 199-205.

Mayor, J.R., Wright, S.J., Turner, B.L., 2014. Species-specific responses of foliar nutrients to long-term nitrogen and phosphorus additions in a lowland tropical forest. Journal of Ecology 102, 36-44.

McKane, R.B., Johnson, L.C., Shaver, G.R., Nadelhoffer, K.J., Rastetter, E.B., Fry, B., Giblin, A.E., Kielland, K., Kwiatkowski, B.L., Laundre, J.A., Murray, G., 2002. Resource-based niches provide a basis for plant species diversity and dominance in arctic tundra. Nature 415, 68-71.

Millard, P., Sommerkorn. M., Grelet, G-A., 2007. Environmental change and carbon 
limitation in trees: a biochemical, ecophysiological and ecosystem appraisal. New Phytologist 175, 11-28.

Miller, A.E., Bowman, W.D., Suding, K.N., 2007. Plant uptake of inorganic and organic nitrogen: neighbor idenitiy matters. Ecology 88, 1832-1840.

Miller, T.E., 1996. On quantifying the intensity of competition across gradients Ecology 77, 978-981.

Mitchell, A.K., 1998. Acclimation of Pacific yew (Taxus brevifolia) foliage to sun and shade. Tree Physiology 18, 749-757.

Muller, B., Pantin, F., Génard, M., Turc, O., Freixes, S., Piques, M., Gibon, Y., 2011. Water deficits uncouple growth from photosynthesis, increase $\mathrm{C}$ content, and modify the relationships between $\mathrm{C}$ and growth in sink organs. Journal of Experimental Botany 62, 1715-1729.

Myers, J.A., Kitajima, K., 2007. Carbohydrate storage enhances seedling shade and stress tolerance in a neotropical forest. Journal of Ecology 95, 383-395.

Nelson, D., Sommers, L.E., 1982. Total carbon, organic carbon, and organic matter. In: Dinauer RC (ed) Methods of Soil Analysis. American Society of Agronomy, Inc. and Soil Science Society of America Inc., Madison, WI, USA, pp. 539-579

O’Brien, M.J., Leuzinger, S., Philipson, C.D., Tay, J., Hector, A., 2014. Drought survival of tropical tree seedlings enhanced by non-structural carbohydrate levels. Nature Climate Change 4, 710-714.

O’Hehir, J.F., Nambiar, E.K.S., 2010. Productivity of three successive rotations of $P$. 
radiata plantations in South Australia over a century. Forest Ecology and Management 259, 1857-1869.

Paul, M., Catterall, C.P., Pollard, P.C. Kanowski, J., 2010. Recovery of soil properties and functions in different rainforest restoration pathways. Forest Ecology and Management 259, 2083-2092.

Pellicer, V., Guehl, J-M., Daudet, F-A., Cazet, M., Riviere, L.M., Maillard, P., 2000. Carbon and nitrogen mobilization in Larix $\times$ eurolepis leafy stem cuttings assessed by dual ${ }^{13} \mathrm{C}$ and ${ }^{15} \mathrm{~N}$ labeling: relationships with rooting. Tree Physiology 20, 807-814.

Richards, A.E., Forrester, D.I., Bauhus, J., Scherer-Lorenzen, M., 2010. The influence of mixed tree plantations on the nutrition of individual species: a review. Tree Physiology 30, 1192-1208.

Sala, A., Piper, F., Hoch, G., 2010. Physiological mechanisms of drought-induced tree mortality are far from being resolved. New Phytologist 186, 274-281.

Schmid, I., Kazda, M., 2002. Root distribution of Norway spruce in monospecific and mixed stands on different soils. Forest Ecology and Management 159, 37-47.

Secchi, F., Zwieniecki, M.A., 2011. Sensing embolism in xylem vessels: the role of sucrose as a trigger for refilling. Plant, Cell \& Environment 34, 514-524.

Soliveres, S., DeSoto, L., Maestre, F.T., Olano, J.M., 2010. Spatio-temporal heterogeneity in abiotic factors modulate multiple ontogenetic shifts between competition and facilitation. Perspectives in Plant Ecology, Evolution and Systematics 12, 227-234. 
1 Sthultz, C.M., Gehring, C.A., Whitham, T.G., 2007. Shifts from competition to facilitation between a foundation tree and a pioneer shrub across spatial and temporal scales in a semiarid woodland. New Phytologist 173, 135-145.

Tilman, D., 1987. On the meaning of competition and the mechanisms of competitive superiority. Functional Ecology 1, 304-315.

Trinder, C.J., Brooker, R.W., Davidson, H., Robinson, D., 2012a. Dynamic trajectories of growth and nitrogen capture by competing plants. New Phytologist 193, 948-958.

Trinder, C.J., Brooker, R.W., Davidson, H., Robinson, D., 2012b. A new hammer to crack an old nut: interspecific competitive resource capture by plants is regulated by nutrient supply, not climate. PLoS ONE 7, e29413.

Trinder, C.J., Brooker, R.W., Robinson, D., 2013. Plant ecology's guilty little secret: understanding the dynamics of plant competition. Functional Ecology 27, 918-929.

Turner, B.L., 2008. Resource partitioning for soil phosphorus: a hypothesis. Journal of Ecology 96, 698-702.

Uhde-Stone, C., Gilbert, G., Johnson, J.M-F., Litjens, R., Zinn, K.E., Temple, S.J., Vance, C.P., Allan, D.L., 2003. Acclimation of white lupin to phosphorus deficiency involves enhanced expression of genes related to organic acid metabolism. Plant and Soil 248, 99-116.

van der Putten, W.H., Bardgett, R.D., Bever, J.D., Bezemer, T.M., Casper, B.B., Fukami, T., Kardol, P., Klironomos, J.N., Kulmatiski, A., Schweitzer, J.A., 
Suding, K.N., van de Voorde, T.F.J., Wardle, D.A., 2013. Plant-soil feedbacks: the past, the present and future challenges. Journal of Ecology 101, $265-276$.

Würth, M.K.R., Peláez-Ried, S., Wright, S.J., Körner, C., 2005. Non-structural carbohydrate pools in a tropical forest. Oecologia 143, 11-24.

Wassen, M.J., Venterink, H.O., Lapshina, E.D., Tanneberger, F., 2005. Endangered plants persist under phosphorus limitation. Nature 437, 547-550.

Wilberts, S., Suter, M., Walser, N., Edwards, P.J., Olde Venterink, H., Ramseier, D., 2014. Testing experimentally the effect of soil resource mobility on plant competition. Journal of Plant Ecology 7, 276-286.

Wiley, E., Huepenbecker, S., Casper, B.B., Helliker, B.R., 2013. The effects of defoliation on carbon allocation: can carbon limitation reduce growth in favour of storage? Tree Physiology 33, 1216-1228.

Yang, M., Ding, G.D., Shi, L., Xu, F.S., Meng, J.L., 2011. Detection of QTL for phosphorus efficiency at vegetative stage in Brassica napus. Plant and Soil $339,97-111$.

Zhu, Y., Li, G.L., Li, Q.M., Liu, Y., Zou, S.Q., Jiang, L., 2011. Influence of continually supplementing nitrogen on the quality of Larix olgensis seedlings. Journal of Nanjing Forestry University 37:44-48. 
1 Table 1. Biomass (mean \pm SE) of L. kaempferi and L. olgensis under different treatments in 2015.

\begin{tabular}{|c|c|c|c|c|c|c|c|c|c|}
\hline Species & & Branch (g) & Stem $(g)$ & Leaf $(g)$ & Shoot (g) & Coarse root (g) & Fine root (g) & Root (g) & Total (g) \\
\hline$L$. & M & $34.31(1.74) \mathrm{e}^{* * *}$ & $24.64(1.70) \mathrm{f}^{* * *}$ & $32.41(2.56) \mathrm{de}^{* * *}$ & $58.95(2.68) \mathrm{g}^{* * *}$ & $12.98(1.01) \mathrm{e}^{\mathrm{ns}}$ & $8.17(0.47) \mathrm{h}^{* *}$ & $21.15(1.45) \mathrm{e}^{*}$ & $112.51(4.94) \mathrm{e}^{* * *}$ \\
\hline \multirow[t]{8}{*}{ kaempferi } & & 58.41(4.32)A & $39.17(2.20)$ & $58.17(2.52) A$ & 97.58(6.41)B & 16.62(1.37)C & $10.36(0.37) \mathrm{D}$ & 26.98(1.33)CD & $182.73(9.85) \mathrm{BC}$ \\
\hline & Mo & $35.41(1.32) \mathrm{e}^{\mathrm{ns}}$ & $29.62(2.66) \mathrm{ef}^{\mathrm{ns}}$ & $32.75(2.56) \mathrm{de}^{* *}$ & $65.03(2.11) \mathrm{fg}^{\mathrm{ns}}$ & $13.85(1.28) \mathrm{e}^{\mathrm{ns}}$ & $7.92(0.97) h^{\mathrm{ns}}$ & $21.77(1.90) \mathrm{e}^{\mathrm{ns}}$ & $119.55(3.56) \mathrm{e}^{*}$ \\
\hline & & $41.35(2.32) \mathrm{B}$ & 32.33(1.34) & 44.97(2.09)B & 73.68(2.84)C & $14.47(0.72) \mathrm{C}$ & $10.08(0.59) D$ & 24.55(1.29)D & 143.20(5.70)D \\
\hline & $\mathrm{S}$ & $67.65(1.82) \mathrm{b}^{\mathrm{ns}}$ & $54.90(3.98) \mathrm{a}^{\mathrm{ns}}$ & $57.00(2.03) \mathrm{b}^{\mathrm{ns}}$ & $122.55(2.92) \mathrm{b}^{\mathrm{ns}}$ & $23.67(0.90) \mathrm{bcd}^{* *}$ & $12.77(0.40) \mathrm{cde}^{\mathrm{ns}}$ & $36.43(1.24) b c^{n s}$ & $215.98(4.76) \mathrm{b}^{\mathrm{ns}}$ \\
\hline & & 67.25(3.84)A & $50.27(2.35)$ & 59.36(3.06)A & 117.52(5.65)A & $17.92(0.86) \mathrm{C}$ & $14.00(0.50) \mathrm{C}$ & 31.92(1.13)C & 208.81(9.60)B \\
\hline & $\mathrm{MN}$ & $59.33(3.48) \mathrm{bc}$ & $44.57(1.92) \mathrm{bcd}$ & $39.48(0.68) \mathrm{cd}$ & $103.90(4.74) \mathrm{cd}$ & $28.76(1.39) \mathrm{b}$ & $14.14(0.56) \mathrm{abc}$ & $42.90(1.80) \mathrm{b}$ & $186.28(6.86) \mathrm{c}$ \\
\hline & $\mathrm{PN}$ & $47.35(1.88) \mathrm{cd}$ & 39.44(1.47)cde & 31.33(1.17)de & $86.79(2.82) \mathrm{de}$ & $21.09(0.67) \mathrm{d}$ & 10.97(0.32)efg & $32.06(0.99) \mathrm{cd}$ & $150.18(3.90) \mathrm{d}$ \\
\hline & $\mathrm{SN}$ & $111.35(3.61) \mathrm{a}$ & $53.77(1.71) \mathrm{ab}$ & $89.08(3.56) \mathrm{a}$ & $165.12(4.68) \mathrm{a}$ & $37.64(0.79) \mathrm{a}$ & $13.67(0.34) \mathrm{abc}$ & $51.31(0.46) \mathrm{a}$ & $305.51(8.28) \mathrm{a}$ \\
\hline$L$. & M & $39.97(1.53) \mathrm{de}^{\mathrm{ns}}$ & $37.80(1.57) \mathrm{de}^{\mathrm{ns}}$ & $35.52(2.20) \mathrm{d}^{\mathrm{ns}}$ & $77.78(2.22) \mathrm{ef}^{\mathrm{ns}}$ & $23.16(1.30) \mathrm{cd}^{*}$ & $10.80(0.56) \mathrm{fg}^{* *}$ & $33.95(1.77) \mathrm{cd}^{\mathrm{ns}}$ & $147.25(4.84) \mathrm{d}^{\mathrm{ns}}$ \\
\hline \multirow[t]{12}{*}{ olgensis } & & 44.61(3.27)B & 40.72(1.47) & $35.20(1.66) B$ & 85.33(4.67)BC & $17.65(0.89) \mathrm{C}$ & $14.79(0.75) \mathrm{C}$ & 32.44(1.61)C & 152.97(7.39)CD \\
\hline & Mo & $26.96(1.58) \mathrm{f}^{* * *}$ & $32.90(2.55) \mathrm{ef}^{\mathrm{ns}}$ & $23.24(1.66) \mathrm{e}^{*}$ & $59.86(3.78) \mathrm{g}^{* * *}$ & $18.76(0.47) \mathrm{d}^{* * *}$ & $10.06(0.34) \mathrm{gh}^{* * *}$ & $28.82(0.62) \mathrm{d}^{* * *}$ & $111.91(5.66) \mathrm{e}^{* * *}$ \\
\hline & & 45.71(1.78)B & 38.78(1.13) & 35.58(3.38)B & $84.49(2.62) B C$ & $24.66(0.61) B$ & $24.37(0.98) B$ & 49.03(1.52)B & $169.10(6.08) \mathrm{CD}$ \\
\hline & $\mathrm{S}$ & $54.89(2.20) \mathrm{bc}^{\mathrm{ns}}$ & $43.36(2.32) \mathrm{cd}^{*}$ & $48.11(1.82) \mathrm{c}^{\mathrm{ns}}$ & $98.25(4.18) \mathrm{cd}^{*}$ & $27.31(0.86) b c^{*}$ & $15.95(0.72) \mathrm{ab}^{* * *}$ & $43.26(1.57) \mathrm{b}^{* * *}$ & $189.62(4.87) \mathrm{c}^{* *}$ \\
\hline & & 63.81(2.77)A & $53.07(2.16)$ & $58.23(4.48) \mathrm{A}$ & $116.89(4.90) \mathrm{A}$ & 35.94(1.71)A & $40.32(1.00) \mathrm{A}$ & $76.26(2.36) \mathrm{A}$ & 251.38(11.23)A \\
\hline & $\mathrm{MN}$ & $51.60(2.95) \mathrm{c}$ & $38.58(1.69) \mathrm{de}$ & 40.92(1.95)cd & $90.18(4.33) \mathrm{de}$ & $26.72(0.97) b c$ & 14.95(0.53)abc & $41.68(1.23) \mathrm{b}$ & $172.78(5.05) \mathrm{cd}$ \\
\hline & $\mathrm{PN}$ & $41.06(2.70) \mathrm{de}$ & $36.72(2.57) \mathrm{de}$ & $35.52(2.42) \mathrm{d}$ & 77.79(4.91)ef & $27.78(1.06) \mathrm{bc}$ & $13.35(0.54) \mathrm{bcd}$ & $41.14(1.57) \mathrm{b}$ & $154.45(8.61) \mathrm{d}$ \\
\hline & $\mathrm{SN}$ & $64.75(3.01) \mathrm{b}$ & 48.79(1.87)abc & $59.17(2.80) \mathrm{b}$ & $113.55(4.78) b c$ & $34.43(1.61) \mathrm{a}$ & $16.07(0.72) \mathrm{a}$ & $50.50(2.30) \mathrm{a}$ & $223.21(5.88) \mathrm{b}$ \\
\hline & $P: F_{N}$ & 0.000 & 0.000 & 0.000 & 0.000 & 0.000 & 0.000 & 0.000 & 0.000 \\
\hline & $P: F_{C}$ & $0.000 \quad \mathbf{0 . 0 0 0}$ & $0.000 \quad \mathbf{0 . 0 0 0}$ & $0.000 \quad \mathbf{0 . 0 0 0}$ & $0.000 \quad \mathbf{0 . 0 0 0}$ & $0.000 \quad \mathbf{0 . 0 0 0}$ & $0.000 \quad \mathbf{0 . 0 0 0}$ & $0.000 \quad \mathbf{0 . 0 0 0}$ & $0.000 \quad \mathbf{0 . 0 0 0}$ \\
\hline & $P: F_{S}$ & $0.000 \quad \mathbf{0 . 1 0 6}$ & $0.261 \quad \mathbf{0 . 0 2 0}$ & $0.000 \quad \mathbf{0 . 0 0 0}$ & $0.000 \quad \mathbf{0 . 8 5 2}$ & $0.000 \quad \mathbf{0 . 0 0 0}$ & $0.000 \quad \mathbf{0 . 0 0 0}$ & $0.000 \quad \mathbf{0 . 0 0 0}$ & $0.000 \quad \mathbf{0 . 0 6 7}$ \\
\hline & $P: F_{S \times C}$ & $0.000 \quad \mathbf{0 . 0 1 9}$ & $0.003 \quad \mathbf{0 . 3 0 5}$ & $0.000 \quad \mathbf{0 . 0 0 7}$ & $0.000 \quad \mathbf{0 . 0 4 1}$ & $0.008 \quad \mathbf{0 . 0 0 0}$ & $0.448 \quad \mathbf{0 . 0 0 0}$ & $0.110 \quad \mathbf{0 . 0 0 0}$ & $0.000 \quad \mathbf{0 . 0 0 1}$ \\
\hline
\end{tabular}




\begin{tabular}{llllllll}
$P: F_{N \times C}$ & 0.642 & 0.050 & 0.000 & 0.173 & 0.338 & 0.000 & 0.003 \\
$P: F_{N \times S}$ & 0.009 & 0.021 & 0.249 & 0.000 & 0.000 & 0.250 & 0.001 \\
$P: F_{N \times S \times C}$ & 0.004 & 0.001 & 0.000 & 0.022 & 0.000 & 0.407 & 0.002 \\
\hline
\end{tabular}

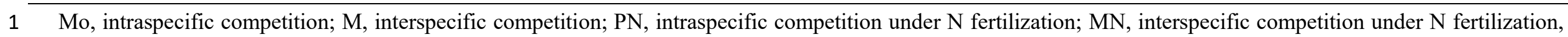

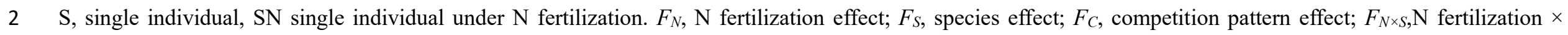

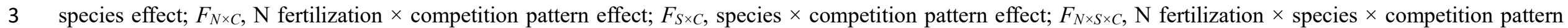

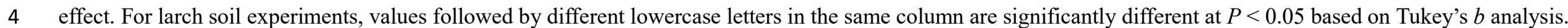

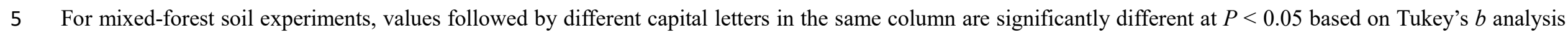
6 (values in bold). ${ }^{* * *} P \leq 0.000,{ }^{* *} 0.000<P \leq 0.01,{ }^{*} 0.01<P \leq 0.05,{ }^{\text {ns }} P>0.05$, Independent-Samples T test between two types of soil. 
3 Figure 1. Relative competitive intensities (RCIs) of L. kaempferi and L. olgensis in

\section{Figure legends}

Cls of Laempferi and L. olgensis in 2014 and at 2015. (a) RCI of the two species in 2014. (b) RCI of the two species in 2015. Larch soil N- indicates L. kaempferi without $\mathrm{N}$ fertilization; larch soil $\mathrm{N}+$ indicates L. kaempferi soil with $\mathrm{N}$ fertilization; mixed-forest soil indicates soil from a secondary forest. Different lowercase letters indicate significant differences between treatments according to Tukey's $b$ test at $P<0.05$. The black and white bars denote $L$. kaempferi and L. olgensis, respectively. For RCI calculation, please see the Methods and materials section.

Figure 2. Variation in element and nonstructural carbohydrate concentrations of $L$. kaempferi and L. olgensis under different treatments from 2014 to 2015. (a), (b) and (c) represent $\mathrm{C}, \mathrm{N}$ and $\mathrm{P}$ concentration changes, respectively; (d), (e) and (f) represent starch, soluble sugar and TNC (total non-structural carbohydrates) concentration changes. Mo, intraspecific competition; $\mathrm{M}$, interspecific competition; PN, intraspecific competition under $\mathrm{N}$ fertilization; $\mathrm{MN}$, interspecific competition under $\mathrm{N}$ fertilization. Different lowercase letters indicate significant differences between $L$. kaempferi and L. olgensis in the larch soil according to Tukey's $b$ test at $P<0.05$. Different capital letters indicate significant differences between L. kaempferi and $L$. olgensis in the mixed-forest soil according to Tukey's $b$ test at $P<0.05$. The red dotted frame indicates treatments in the mixed-forest soil. ${ }^{* * *} P \leq 0.000,{ }^{* *} 0.000<P$ 
$1 \leq 0.01,{ }^{*} 0.01<P \leq 0.05,{ }^{\mathrm{ns}} P>0.05$, Independent-Samples $\mathrm{T}$ test between the two

2 types of soil. The bars with and without oblique lines denote L. kaempferi and $L$.

3 olgensis, respectively. The white, grey and black portions denote roots, shoots and 4 leaves, respectively.

6 Figure 3. $\mathrm{C}, \mathrm{N}$ and $\mathrm{P}$ content accumulation ratios in leaves, shoots and roots as well $7 \quad$ as in the whole plant in L. kaempferi and L. olgensis under different treatments from 82014 to 2015. (a), (c) and (e) represent C, N and P content accumulation ratios in 9 leaves, shoots and roots, respectively; (b), (d) and (f) represent C, N and P content accumulation ratios in the whole plant, respectively. Mo, intraspecific competition; M, interspecific competition; $\mathrm{PN}$, intraspecific competition under $\mathrm{N}$ fertilization; $\mathrm{MN}$, interspecific competition under $\mathrm{N}$ fertilization. Different lowercase letters indicate significant differences between L. kaempferi and L. olgensis in the larch soil according to Tukey's $b$ test at $P<0.05$. Different capital letters indicate significant differences between L. kaempferi and L. olgensis in the mixed-forest soil according to Tukey's $b$ test at $P<0.05$. The red dotted frame indicates treatments in the mixed-forest soil. ${ }^{* * *} P \leq 0.000,{ }^{* *} 0.000<P \leq 0.01,{ }^{*} 0.01<P \leq 0.05,{ }^{\text {ns }} P>0.05$, Independent-Samples T test between the two types of soil. The bars with and without oblique lines denote L. kaempferi and L. olgensis, respectively. The white, grey and black portions denote roots, shoots and leaves, respectively.

Figure 4. Non-structural carbohydrate content accumulation ratios in leaves, shoots 
1 and roots as well as in the whole plant in L. kaempferi and L. olgensis under different

2 treatments from 2014 to 2015. (a), (c) and (e) represent starch, soluble sugar and TNC

3 (total non-structural carbohydrates) content accumulation ratios of leaves, shoots and

4 roots, respectively; (b), (d) and (f) represent starch, soluble sugar and TNC content

5 accumulation ratios of the whole plant, respectively. Mo, intraspecific competition; M,

6 interspecific competition; $\mathrm{PN}$, intraspecific competition under $\mathrm{N}$ fertilization; $\mathrm{MN}$,

7 interspecific competition under $\mathrm{N}$ fertilization. Different lowercase letters indicate

8 significant differences between L. kaempferi and L. olgensis in the larch soil

9 according to Tukey's $b$ test at $P<0.05$. Different capital letters indicate significant

10 differences between L. kaempferi and L. olgensis in the mixed-forest soil according to

11 Tukey's $b$ test at $P<0.05$. The red dotted frame indicates treatments in the

12 mixed-forest soil. ${ }^{* * *} P \leq 0.000,{ }^{* *} 0.000<P \leq 0.01,{ }^{*} 0.01<P \leq 0.05,{ }^{\text {ns }} P>0.05$,

13 Independent-Samples T test between the two types of soil. The bars with and without

14 oblique lines denote L. kaempferi and L. olgensis, respectively. The white, grey and

15 black portions denote roots, shoots and leaves, respectively. 

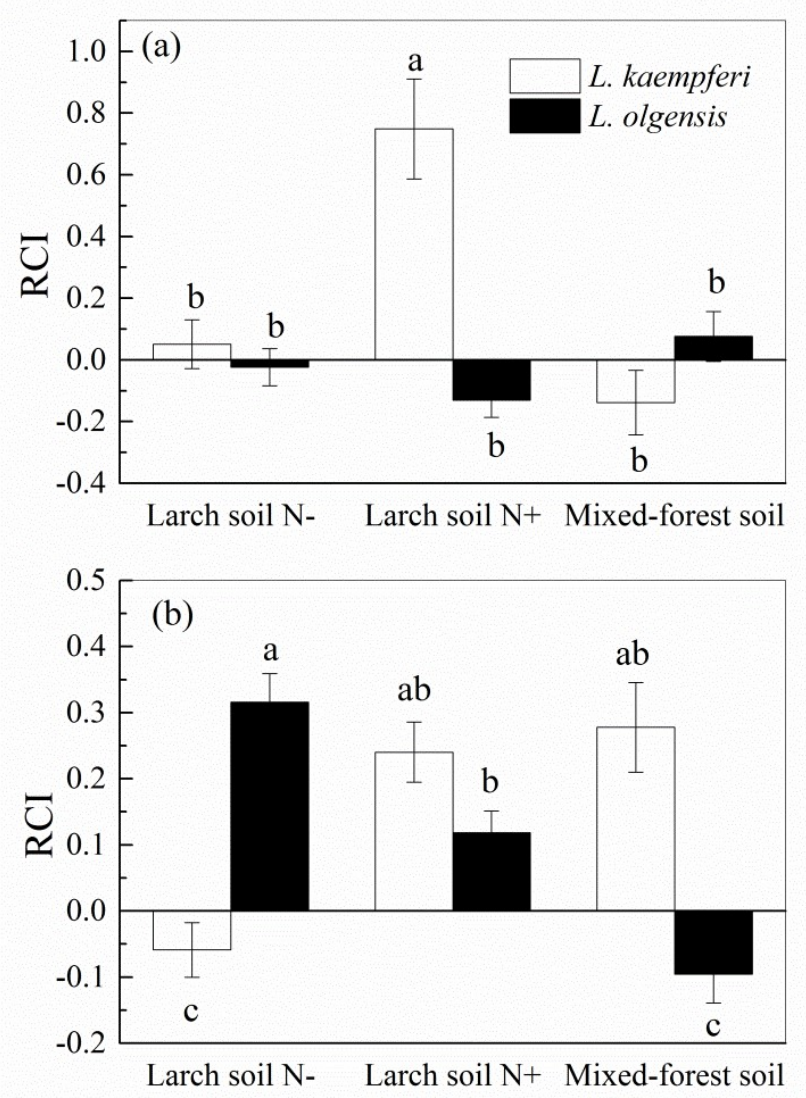

2

3

4

5

6

7

8

9 

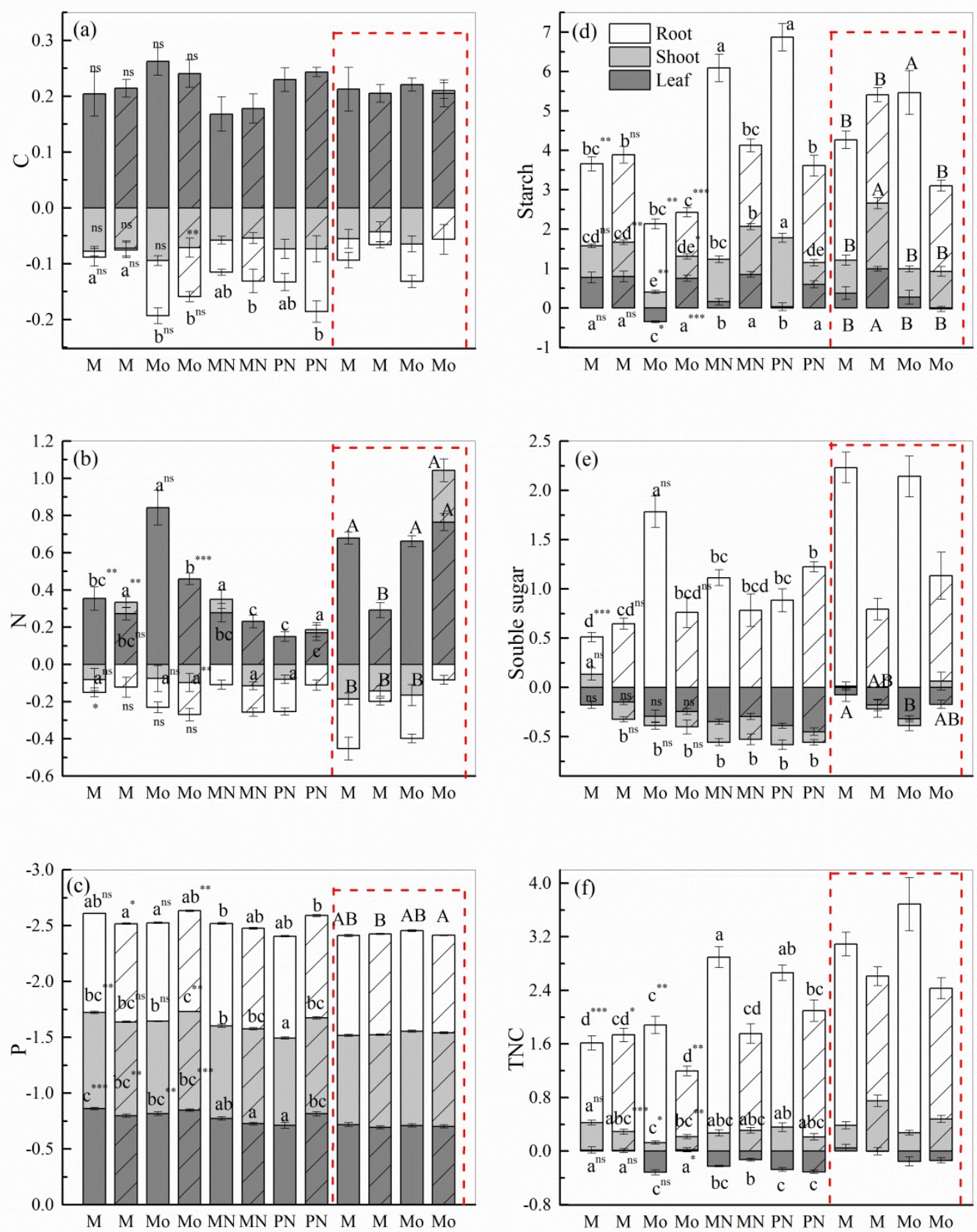

2 
Figure 3
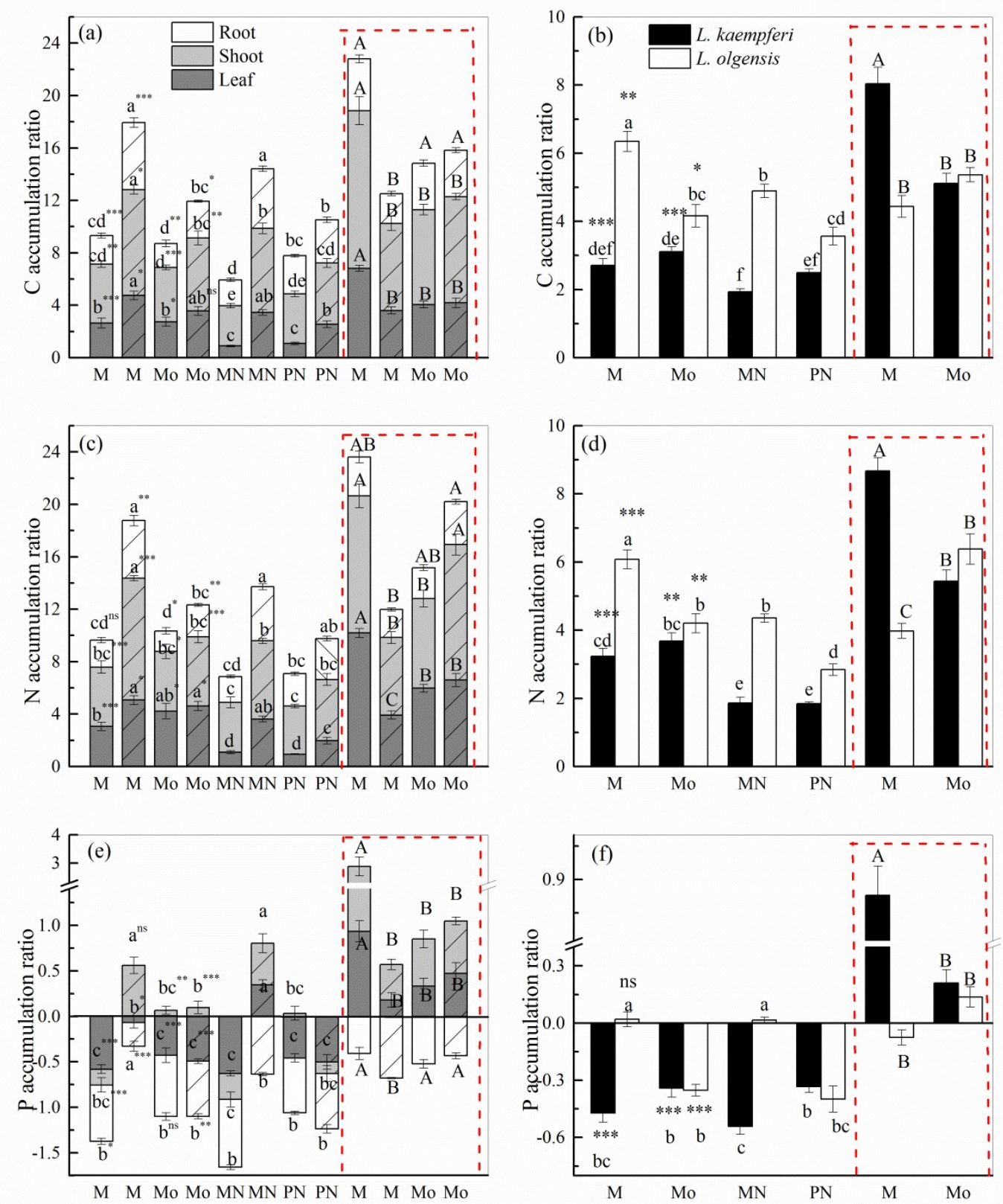
Figure 4
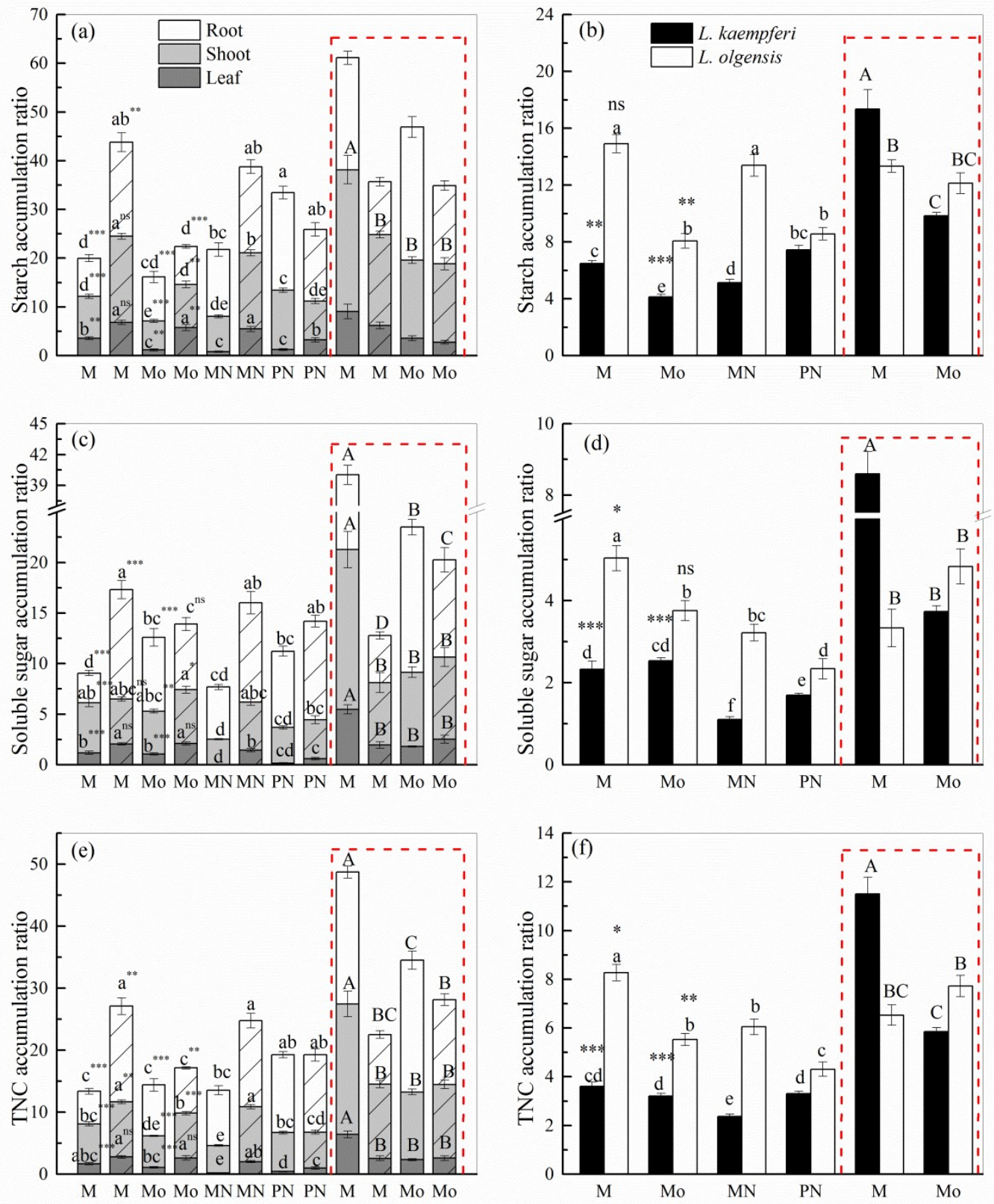